\title{
Effects of Glycyrrhizic Acid on Productive and Immune Parameters of Broilers
}

\section{-Author(s)}

\author{
Ocampo $\mathrm{CL}^{\prime}$ \\ Gómez-Verduzco G" \\ Tapia-Perez GIII \\ Gutierrez OL \\ Sumano LH
}

Departamento de Fisiología y Farmacología, Facultad de Medicina Veterinaria y Zootecnia. Universidad Nacional Autónoma de México. Av. Universidad 3000, Coyoacán, México City 04360, Mexico.

" Departamento de Producción Animal Aves. Facultad de Medicina Veterinaria y Zootecnia. Universidad Nacional Autónoma de México. Av. Universidad 3000, Coyoacán, México City 04360, Mexico.

II Departamento de Genetica y Bioestadistica, Facultad de Medicina Veterinaria y Zootecnia, Universidad Nacional Autonoma de Mexico, Av. Universidad 3000, Coyoacan, Mexico City 04510

\section{-Mail Address}

Corresponding author e-mail address Héctor Sumano DVM, MD, PhD

Departamento de Fisiología y Farmacología, Facultad de Medicina Veterinaria y Zootecnia. Universidad Nacional Autónoma de México. Av. Universidad 3000, Coyoacán, México City 04620, Mexico.

Tel: $\quad+$ +(52) 5556225908 ext 104

Fax: $\quad+$ (52) 5556225908 ext 102

Email: sumano@unam.mx

\section{Eeywords}

Broiler chickens, growth promotion, immune system, glycyrrhizic acid.

\section{ABSTRACT}

Considering that glycyrrhizic acid (GRA) has been shown to have in-vitro and in-vivo antiviral activity against a wide range of viruses as well as immunostimulating activity, a trial to evaluate its effects on the performance and the immune response against Newcastle disease of broiler chickens was carried out. The study was performed with oneday-old Ross $x$ Ross broiler chickens. GRA was added to the drinking water throughout the $49-d$ production cycle at a dose of $0.03 \%$. Sample size of the trial was established in a pilot assay. Results showed that broiler chickens treated with GRA presented better weight gain, final body weight, feed conversion ratio, and lower mortality rate than the non-treated controls. In addition, GRA-treated birds presented higher antibody titers against Newcastle disease virus and more efficient cellular immune response, as demonstrated by the late-hypersensitivity response test. Blood lymphocyte and thrombocyte counts also increased in this group. The histopathological examination of the bursa, spleen, and thymus revealed that only the thymus of the GRA-treated group had a clearly defined increase in cortex thickness on day 49. The bursa showed a higher number of lymphoid lesions in CG on days 21 and 49 compared with the GRA group. These results suggest that GRA has growth promotion properties, which are possibly linked to immunebased effects.

\section{INTRODUCTION}

Low cost, high quality, and the efficient production of large quantities of broiler meat are key goals of modern poultry production. The efforts to improve production performance have placed particular emphasis on biosecurity, nutrition, vaccination, timely and adequate intervention with antibacterial drugs and, when accepted by regulatory agencies, by the inclusion of antibiotic growth promoters in the feed (Castanon, 2007). It has also been postulated that products that can optimize or boost the immune response may not only benefit the health status of flocks, but also improve live performance (Cox \& Dalloul, 2010).

Adequate animal management allows the proper function of nonspecific immune mechanisms, such as body temperature, anatomic features, respiratory tract cilia, and normal microflora, while specific immune mechanisms (acquired immunity), which are characterized by specificity, heterogeneity and memory, may require chemical intervention to improve cellular and non-cellular (humoral) immunity. The non-cellular components include immunoglobulins (antibodies) and the cells which produce them, and the cellular component includes all the cells that react with specificity to antigens, except those associated with antibody production.

Although specific immune responses of avian species are common to those of other animal species, some differences are observed. Chickens 
Ocampo CL, Gómez-Verduzco G, Tapia-Perez G, Gutierrez OL, Sumano LH
Effects of Glycyrrhizic Acid on Productive and Immune Parameters of Broilers have a different repertoire of immune genes, molecules, cells, and tissues compared with mammals. However, the basic principal of innate immune responses driving appropriate adaptive immune responses to clear initial infection and provide immunological memory remains constant for all vertebrate species so far studied, including the chicken (Kaiser, 2010).Together, non-specific and specific immune mechanisms of the chicken are very effective in preventing diseases and helping to ensure maximum productive potential.

In commercial broiler production, drug preparations to improve both the immune status and the performance should ideally be administered orally, be safe to the birds, and not pose any risks to public health. Encouraging results have been obtained in poultry production with the DNA-containing preparation CpG-ODN ${ }^{\circledR}$, and with a patented version of Aloe vera aqueous extract (Gomis, et al., 2003; Durrani, et al. 2008). Another potentially useful immune-stimulating pharmaceutical preparation based on glycyrrhizic acid (GRA) has been used in human medicine. It is claimed that GRA-based drug preparations extracted from licorice stimulate the production of gamma interferon in humans (Sugawara, 1986; Dai, 2001), and such preparations are usually classified as nutraceutical by local regulatory agencies, such as the Ministry of Health of Mexico (Secretaria de Salud).

Glycyrrhizic acid has been shown to possess a liver protective effect (Vilar et al., 2009; Gomez, et al., 2010; García, et al. , 2010; Kang \& Zohou, 2005). It has in-vitro and in-vivo antiviral activity, interfering with DNA and RNA replication of a wide range of viruses, including herpes, influenza $A$ and $B$, hepatitis $B$, coronavirus, and SARS (Pompei, et al., 1979; Hirabayashi et al., 1991; Badam, 1994; Lin, 2003; Hoever, et al. 2005; Lee, et al., 2007). This pharmaceutical preparation has also been demonstrated to be able to prevent the virion from hatching from its capsid (Pompei, et al., 1979; Lin, 2003), apparently due to a dose-dependent inhibition of kinase-P phosphorylation (Chavali, et al., 1987; Ohtsuki and Ishida, 1988). In addition, GRA has been shown to interfere with arylamine $\mathrm{N}$-acetyltransferase bacterial activity, thereby exhibiting antibacterial effects, at least against Streptococcus spp., Haemophilus spp., and Klebsiella spp. (Lo, 1997; Krausse et al., 2004). Ocampo et al. (2014) found that addition of GRA to shrimp diets increased the survival rate of shrimp affected in white spot syndrome virus.

Based on these evidences, the aim of this trial was to evaluate if the GRA oral supplementation in the drinking water could improve the performance of broilers, while stimulating their humoral and cellular immune responses. Additionally, a basic screening of parameters for liver integrity were performed to assess whether or not a measurable change could be detected in GRA-medicated broiler chickens.

\section{MATERIALS AND METHODS}

This study was approved by the Institutional Committee of Research, Care and Use of Experimental Animals of the Universidad Nacional Autónoma de Mexico, according to the Mexican Official Regulation NOM-062-ZOO-1999.

The study was performed in two parts: first, a pilot assay was conducted to determine the possible dose of GRA and the sample size required for further repetitions, using the GPower program (Buchner, et al., 1997). The endpoint used for performance parameters were the differences between the percentages of cumulative mortality of the control and treated birds, and the immune parameter was antibody titers against Newcastle disease virus. The formulas used to determine sample size were as follows:

\section{Proportion differences}

$$
n=\frac{2(\bar{p})(1-\bar{p})\left(Z_{\beta}+Z_{\alpha / 2}\right)^{2}}{\left(p_{1}-p_{2}\right)^{2}}
$$

$(\bar{p}) \overline{1-(p)}$ A measure of variability (similar to standard deviation)

p1 and p2 are the cumulative proportions of mortality in the pilot assay.

$Z_{\beta}$ represents the desired power (typically $80 \%$ power).

$Z_{\alpha / 2}$ represents the desired level of statistical significance (typically 1.96)

2. Difference of log2-transformed means

$$
\mathrm{n}=\frac{2 \sigma^{2}\left(Z_{\beta}+Z_{\alpha / 2}\right)^{2}}{\text { difference }^{2}}
$$

$\sigma 2$ Standard deviation of the outcome variable

$Z_{\beta}$ represents the desired power (typically $80 \%$ power).

$Z_{\alpha / 2}$ represents the desired level of statistical significance (typically 1.96)

Difference ${ }^{2}$ effect size (the difference among means) 
Ocampo CL, Gómez-Verduzco G, Tapia-Perez G, Gutierrez OL, Sumano LH
Effects of Glycyrrhizic Acid on Productive and Immune Parameters of Broilers

\section{PILOT PHASE}

\section{Broilers and treatment}

The study was performed on a commercial farm located in the state of Queretaro, Mexico, with three flocks of one-day-old Ross $x$ Ross broiler chickens, which were randomly assigned to an untreated control group (CG) and the experimental GRA-treated group (VG). Feed and water were provided ad libitum.

All birds were fed a commercial corn- and soybean-based broiler diet (Premium formulation, Malta Clayton, México City), formulated to meet their nutrient requirements during three rearing phases, as recommended by the National Research Council (Table 1).

Table 1 - Ingredients and feed composition of the basal pre-starter, starter, and finisher diets.

\begin{tabular}{lccc}
\hline Ingredient & Pre-starter & Starter & Finisher \\
\hline Yellow corn & & & \\
Sorghum & 531.065 & 564.050 & 620.300 \\
Soybean meal & 315.000 & 274.000 & 240.000 \\
Canola & 60.000 & 60.000 & 40.000 \\
Acidulate & 44.000 & 53.000 & 55.000 \\
Pigment 15\% & - & 4.000 & 19.120 \\
Calcium 30\% & 27.000 & 22.000 & 1.480 \\
Orthophosphate 21\% & 9.300 & 8.300 & 3.400 \\
Lysine & 2.800 & 4.000 & \\
Methionine & 3.350 & 3.650 & 3.600 \\
Threonine & 0.385 & & 0.500 \\
Salt & 3.600 & 3.500 & 3.000 \\
Coccidiostat & 0.500 & 0.500 & \\
Vitamin and mineral premix & 3.000 & 3.000 & \\
Total (kg) & 1,000 & 1,000 & 1,000 \\
\hline Nutrient composition & & & \\
\hline Protein, \% & 22.000 & 20.000 & 18.000 \\
\hline Metabolized energy (Mkal) & 3.000 & 3.100 & 3.175 \\
\hline
\end{tabular}

Natural liquorish extract powder, containing 20\% GRA (Daxinganling Lingonberry Boreal Biotech Co., Ltd. China) was first diluted in water and the solution was then added to the drinking water at a rate of $0.03 \%(\mathrm{w} / \mathrm{v})(60 \mu \mathrm{g}$ of $\mathrm{GRA} / \mathrm{mL}$ of water) throughout the 49-d production cycle established for this trial, totaling approximately414 $\mathrm{mg} / \mathrm{kg}$ at the end of the cycle, considering a total water intake during seven weeks of $6,900 \mathrm{~mL}$. Cumulative mortality was recorded in week 7.

\section{Humoral immune response}

All broiler chickens were vaccinated against Newcastle disease virus (NDV) at 10 days of age by the subcutaneous (SC) injection in the region of the neck, delivering $1 \mathrm{~mL}$ of an inactivated vaccine emulsion against Newcastle strain B1 (Newca-mex ${ }^{\circledR}$, Avimex -
Animal Health; Mexico City). Simultaneously, birds were inoculated by eye drop (approximately $0.03 \mathrm{~mL} /$ chicken) with an attenuated live virus vaccine against "LaSota" strain (lasota ${ }^{\circledR}$ Avimex - Animal Health, Mexico City). The effect of GRA on the humoral immune response was evaluated by testing blood hemagglutinating antibody titers (log2-transformed means) against NDV 49 days post-vaccination (18 samples per treatment) by the hemagglutination-inhibition assay (Brugh et al., 1978,). Blood samples were collected from the wing vein, immediately centrifuged, and the serum was separated and frozen at $-20^{\circ} \mathrm{C}$ until analyses within one week.

\section{Pilot phase and statistical analysis}

Analysis of this phase focused on the differences in cumulative mortality and the log2-transformed mean antibody titers against NDV between the control and treated groups as endpoints of the study and with 104 broiler chicken per group (see Table 2).

Table 2 - Results of the pilot assay for cumulative mortality in week 7 and antibody titers against Newcastle disease virus on day 49 .

\begin{tabular}{lccc}
\hline & $\begin{array}{c}\text { Cumulative } \\
\text { mortality }(\%)^{1}\end{array}$ & Antibody titers $^{2}$ & Sample size $^{3}$ \\
\hline Glycyrrhizic acid & 5.95 & $6.93 \pm 1.3$ & $52 / 52=104$ \\
Control & 8.17 & $6.91 \pm 1.6$ & $52 / 52=104$ \\
\hline
\end{tabular}

'Cumulative mortality in week 7.

${ }^{2}$ Mean \pm SD on day 49.

${ }^{3}$ Obtained by GPower program (group GRA-G/CG) $n=104 /$ group .

\section{SECOND PHASE}

The second phase of this study was performed on a commercial farm located in the state of Queretaro, Mexico, with a total of 60,000 one-day-old Ross $x$ Ross broiler chicks, which were randomly assigned to two groups: the untreated control group (CG) and the experimental GRA-treated group (GRA-G), with 30,000 broilers per group and three replicates of 10,000 each, allocated so as to have both groups in each chicken house, separated only by a wire mesh. Broiler chickens were fed as in the pilot phase (Table 1). The GRA-G was also medicated with GRA as for the pilot phase.

\section{Mortality and body weight gain}

From each replicate of 10,000 broilers, 20 were randomly separated to evaluate 60 broilers in the GRA-G and 60 in the CG, in duplicate. In these birds, individual body weight and group-feed intake were measured weekly. Cumulative weight gain and feed conversion ratio were also determined. Number of 
Ocampo CL, Gómez-Verduzco G, Tapia-Perez G, Gutierrez OL, Sumano LH
Effects of Glycyrrhizic Acid on Productive and Immune Parameters of Broilers chicken deaths in the whole poultry house and their post-mortem analysis to determine the cause of death, were also recorded.

\section{Humoral immune response}

This was carried out as described for the pilot phase.

\section{Cellular immune response}

The cellular immune response was determined using a cutaneous basophilic hypersensitivity test in 52 birds per treatment on days 21 and 49 (Edelman, et al., 1985; Lanckriet, et al., 1990). Briefly, an intradermal injection of phytohemagglutinin-P (Sigma Chemical; St. Louis, MO, USA) $(150 \mu \mathrm{g} / 0.1 \mathrm{~mL})$ was administered in the inter-digital membrane of $3^{\text {rd }}$ and $4^{\text {th }}$ phalanges of the right foot. Sterile saline solution $(0.1 \mathrm{~mL})$ injected into the left foot was used as a reference. Twentyfour hours post-injection, the thickness of the interdigital membrane was measured in millimeters using a Vernier caliper.

\section{Hematology and blood chemistry}

Blood samples were taken with an S-Monovette EDTA collection tube (Sarstedt, $\mathrm{S}$ de RL de CV, Mexico) from the radial vein of 52 birds from both groups (CG and GRA-G) on days 21 and 49. Blood smears were stained with Wright's techniques, cell counts were carried out individually, and percentages for each cell type calculated. In addition, serum samples were obtained as previously described, and the levels of aspartate amino transferase (AST), glucose, glutamate dehydrogenase (GLDH), total plasma protein (PP), albumin, and globulins were determined (Dein, 1984) in an attempt to detect a change in liver integrity.

\section{Score of lymphoid tissue injury}

Ten randomly selected chickens from GRA-G and CG were sacrificed at 21 and 49 days of age. The bursa, spleen and thymus were separated and fixed in $10 \%$ buffered formalin, processed, and stained with hematoxylin-eosin for histopathology under light microscopy to determine the degree of injury and thickness of each of these lymphoid organs in terms of maturity of lymphoid cells found, as suggested by Gholamiandehkordi et al. (2007). Briefly, bursa evaluation was based on visual injury scores on 0-4 analog scale, the highest degree of injury and adding to the degree of injury the value of the dissemination of such injury and the number of bursas with similar lesions, in a given group. For the thymus, a longitudinal section of the right thymus chain was made to obtain the proportion of the cortex and medullar width. The proportion was expressed as the proportion of the medulla considering the sum in $\mathrm{mm}$ of the cortex and medullar width as $100 \%$. The spleen was assessed by counting the number of follicles in at least five microscopic fields (10X) randomly selected along a transversal line crossing the section of the organ (Ortiz et al., 2001).

\section{Statistical analysis}

The IBM SPSS $19 \AA^{\circledR}$ statistical package was used for all analyses (Arbickle, 1995). Performance variables were analyzed by the model of analysis of variance with repeated measures (Vilar, et al. 2007). The hematological index on days 21 and 49 was analyzed by the " $\mathrm{t}$ " test. Cumulative mortality was analyzed by the Chi-squared test. Antibody titers in both experiments were log2 transformed and analyzed by the regression method. Statistical significance was set at $p<0.05$.

\section{RESULTS}

\section{Body weight gain and mortality in the second phase}

The birds in GRA-G presented higher cumulative weight gain $(p=0.005)$, and better feed conversion ratio ( $p=0.03$ ) compared with the CG birds. Results are summarized in Table 3. Glycyrrhizic acid-treated broilers presented statistically lower mortality rate compared with the control group $(p=0.014)$. Cumulative mortalities at the end of the cycle were 5.95 and 8.17 for the GRA-G and the CG, respectively $(p<0.05)$.

\section{Humoral immune response}

A positive humoral response to the commercial preparation of glycyrrhizic acid was found in this trial, as assessed by antibody titers against Newcastle disease virus. The GRA-G birds showed a 1 log difference in hemagglutinating antibody titers against this virus compared with CG birds on day 21 (6.93 vs. 5.53) $(p=0.05)$ and a 5 log difference on day 49 (10.5 vs. 5.53) ( $p=0.001)$. Results are summarized in Table 4.

\section{Cellular Immune Response}

The delayed basophilic hypersensitivity test showed an increase in interdigital thickness in GRA-G compared with CG on day 21 (0.776 vs. $0.161 \mathrm{~mm}$ ). Statistically significant difference was also obtained on day 49 (0.590 vs. $0.202 \mathrm{~mm}$ for GRA-G and CG, respectively) $(p<0.01$ in both instances), representing a 4.8 and 2.9 fold increments in thickness on days 21 and 49, respectively (Table 4). 
Ocampo CL, Gómez-Verduzco G, Tapia-Perez G, Gutierrez OL, Sumano LH

Table 3 - Mean \pm 1 SD of cumulative weight gain, cumulative mortality, and cumulative feed conversion ratio (FCR) of Ross $x$ Ross broiler chickens in the untreated control group (CG) and the glycyrrhizic acid-treated group (GRA-G).

\begin{tabular}{|c|c|c|c|c|c|c|}
\hline \multirow[t]{2}{*}{ Week $^{1}$} & \multicolumn{2}{|c|}{ Cumulative weight gain $(\mathrm{kg})^{1}$} & \multicolumn{2}{|c|}{ Cumulative mortality $(\%)^{2}$} & \multicolumn{2}{|c|}{ Cumulative feed conversion ratio ${ }^{2}$} \\
\hline & GRA-C & CG & GRA-C & CG & GRA-C & CG \\
\hline 1 & $0.15 \pm 0.001$ & $0.14 \pm .0001$ & 0.67 & 0.64 & $1.01 \pm 0.026$ & $1.09 \pm 0.030$ \\
\hline 2 & $0.32 \pm 0.005$ & $0.30 \pm 0.004$ & 1.27 & 1.18 & $1.25 \pm 0.015$ & $1.26 \pm 0.017$ \\
\hline 3 & $0.65 \pm 0.010$ & $0.63 \pm 0.012$ & 1.63 & 1.90 & $1.44 \pm 0.014$ & $1.48 \pm 0.017$ \\
\hline 4 & $1.18 \pm 0.080$ & $1.16 \pm 0.062$ & 2.45 & 3.36 & $1.51 \pm 0.011$ & $1.66 \pm 0.015$ \\
\hline 5 & $1.66 \pm 0.095$ & $1.64 \pm 0.012$ & 4.15 & 5.74 & $1.64 \pm 0.012$ & $1.81 \pm 0.013$ \\
\hline 6 & $2.50 \pm 0.090$ & $2.22 \pm 0.100$ & 4.27 & 6.98 & $1.78 \pm 0.010$ & $1.99 \pm 0.012$ \\
\hline 7 & $3.10 \pm 0.098$ & $2.88 \pm 0.010$ & 5.95 & 8.17 & $1.94 \pm 0.011$ & $2.15 \pm 0.012$ \\
\hline
\end{tabular}

$n=30,000$ Ross $x$ Ross broiler chickens per group divided in three replicates.

'The performance variables were determined weekly in 50 randomly-selected chickens per replicate.

${ }^{2}$ There were significant performance parameters between the treated and control groups. Cumulative weight gain $(p=0.005, A N O V A)$, cumulative mortality $\left(p=0.014, \chi^{2}\right.$ test), and cumulative feed conversion ratio ( $p=0.03$, ANOVA).

\section{Hematology and blood chemistry}

No hematological or blood chemistry effects were detected when medicating broilers with glycyrrhizic acid via drinking water $(0.03 \%)$ throughout the 49 day production cycle. Most hematological and blood chemistry parameters of the GRA-G birds remained unaltered when compared with CG birds. Exceptions were lymphocyte and thrombocyte counts, which increased in GRA-G ( $p=0.042$ and $p=0.05$, respectively) (Table 4).

\section{Lesion score in lymphoid tissue}

The histopathological evaluation of the thymus on day 49 revealed a clearly defined increase in cortex thickness in GRA-G as shown in Figure $1(p=0.032)$. However, no major pathological changes were observed, except for the bursa, which showed a higher number of lymphoid lesions in CG on days 21 and 49 compared with GRA-G $(p=0.008)$ (Table 4).

\section{DISCUSSION}

The worldwide trend to limit and even ban the use of antibacterial drugs in poultry feeds for growth promotion, has created the need for alternative solutions that improve performance while not damaging flock health. From such a perspective, the use of GRA as additive in the drinking water is proposed as a viable alternative to improve both production and health of the flock. Broiler chickens treated in this trial with $0.03 \%$ glycyrrhizic acid showed statistically better weight gain (7.6\% higher), and a better feed conversion ratio as compared to the non-treated ones, and their mortality was reduced from $8.17 \%$ to $5.95 \%$. Although ANOVA for repeated measurements eliminates the statistical effect of individuals, and therefore, results can be better ascribed to treatment
(Vilar et al. 2007), the sample size to upgrade the power of the test ( 0.8 in this trial) should be increased. Additionally, a detailed cost-benefit analysis under various husbandry scenarios is required, considering,
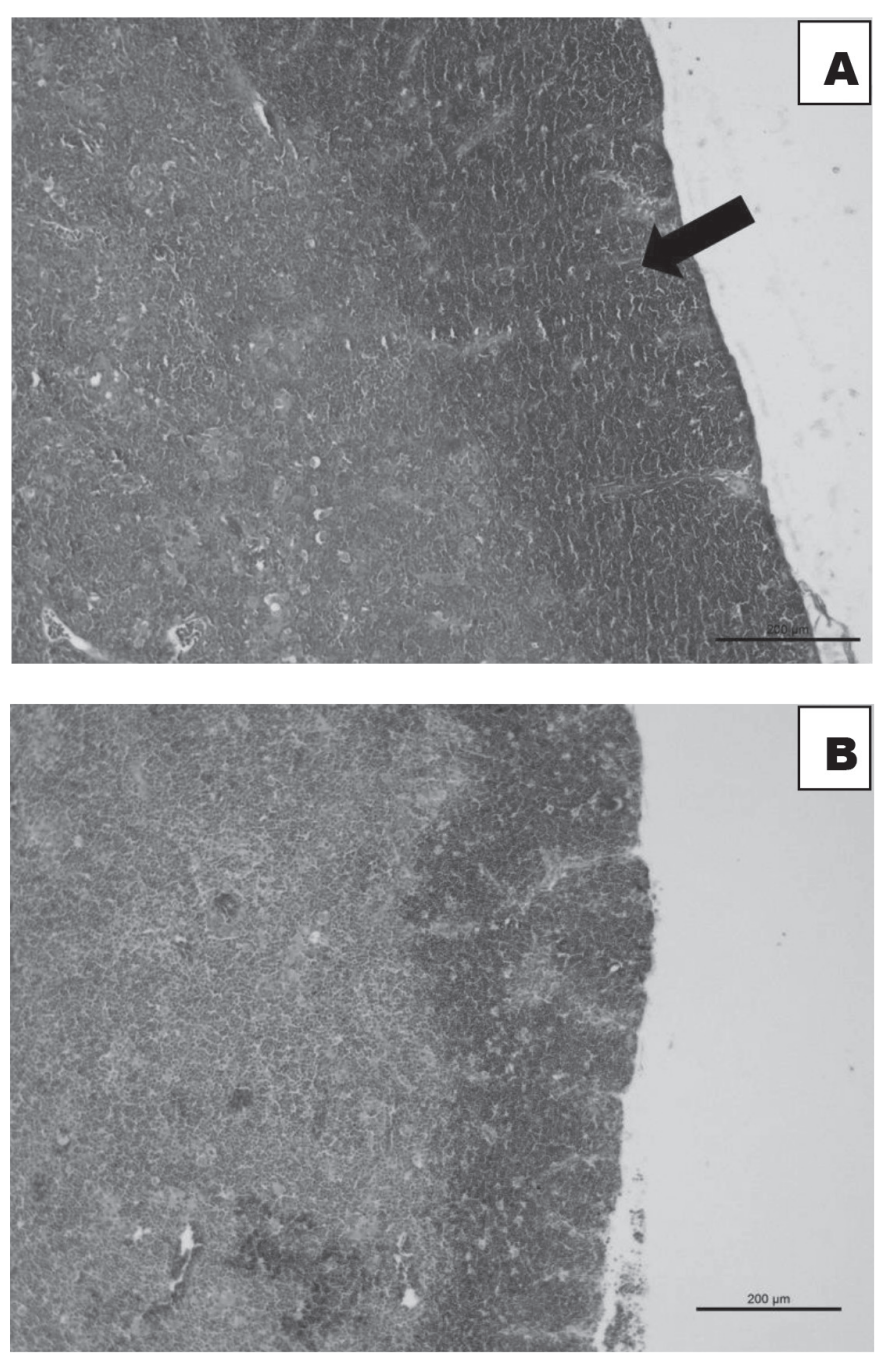

Figure 1 - Broiler, 49 days, thymus. (A) Treated group. A clearly defined increase in cortex thickness (arrow) becomes apparent on day 49 of continuous treatment with glycyrrhizic acid. (B) untreated and control group: the cortex is thinner than in (A). 
Ocampo CL, Gómez-Verduzco G, Tapia-Perez G, Gutierrez OL, Sumano LH
Effects of Glycyrrhizic Acid on Productive and Immune Parameters of Broilers

Table 4 - Mean \pm 1 SD of hematological, histological and immune responses of Ross $x$ Ross broiler chickens either treated with glycyrrhizic acid (GRA-G) or untreated (control group, CG) on days 21 and 49 of the production cycle.

\begin{tabular}{|c|c|c|c|c|}
\hline Parameter & $\begin{array}{c}C G \\
21 d\end{array}$ & $\begin{array}{c}\text { GRA-G } \\
21 \mathrm{~d}\end{array}$ & $\begin{array}{c}C G \\
49 d\end{array}$ & $\begin{array}{c}\text { GRA-G } \\
49 \mathrm{~d}\end{array}$ \\
\hline Lymphocytes $^{1}$ & $3.37 \pm 1.02^{a}$ & $4.61 \pm 1.03^{b}$ & $5.05 \pm 0.03^{a}$ & $5.53 \pm 0.032^{b}$ \\
\hline Thrombocytes ${ }^{2}$ & $12.7 \pm 1.31^{a}$ & $16.4 \pm 1.50^{b}$ & $17.3 \pm 1.36^{a}$ & $20.6 \pm 2.01^{b}$ \\
\hline Bursa $^{3}$ & $4.1 \pm 1.2^{\mathrm{a}}$ & $2.4 \pm 0.95^{b}$ & $4.07 \pm 1.02^{\mathrm{a}}$ & $4.67 \pm 1.1^{b}$ \\
\hline Thymus cortex 4 & $366.3 \pm 3.8^{a}$ & $378.96 \pm 4.1^{b}$ & $130.49 \pm 2.3^{a}$ & $294.38 \pm 5.7^{b}$ \\
\hline Antibody titers ${ }^{5}$ & $5.53 \pm 1.00^{a}$ & $6.93 \pm 1.30^{b}$ & $5.60 \pm 1.20^{a}$ & $10.5 \pm 1.65^{b}$ \\
\hline $\mathrm{RHC}(\mathrm{mm})^{6}$ & $0.161 \pm 0.12^{\mathrm{a}}$ & $0.776 \pm 0.32^{b}$ & $0.202 \pm 0.11^{\mathrm{a}}$ & $0.590 \pm 0.20^{b}$ \\
\hline
\end{tabular}

'Lymphocyte counts.

${ }^{2}$ Thrombocyte counts $\times 10^{9} / \mathrm{L}$.

${ }^{3}$ Average bursa injury score.

${ }^{4}$ Cortex thickness in $\mu \mathrm{m}$.

${ }^{5} \mathrm{RHC}=$ response to skin hypersensitivity.

${ }^{6}$ Antibodies obtained by hemagglutination inhibition test for Newcastle disease virus.

$a, b$ Values in the same rows for days 21 and 49 with different superscripts are significantly different $(p<0.05)$.

for instance, the presence of hard water in the farm, different broiler strains, heat stress, etc. In addition, economic considerations, such as meat market price and cost-benefit ratios, would need to be accounted for, in a multicenter type analysis.

Although the results of this study are positive in terms of health and performance, generalization should be avoided as there are other chemical forms of GRA. Each would require individual analysis. For example, diammonium glycyrrhizin was shown to have a protective effect against infectious bronchitis viruses in chickens (Castanon, 2007), but little or no experiments with GRA, de-glycyrrhizic acid, zinc glycyrrhizate, dipotassium glycyrrhizinate, and otherlicorice extracts are available. In any case, glycyrrhizic acid can hardly be regarded as a drug preparation, which would require detailed studies to define any possible health risks to humans caused by its residues in meat.

The regular intake of $100 \mathrm{mg}$ glycyrrhizic acid/day was defined as the lowest observed adverse effect level in humans, using a safety factor of 10 , and the daily intake of $10 \mathrm{mg}$ glycyrrhizic acid was considered safe for most healthy adults (Størmer, et al., 1993). In this trial the end-cumulative dose of GRA for each chicken after seven weeks of continuous medication was only $414 \mathrm{mg} / \mathrm{kg}$, with an approximate daily dose of $48 \mathrm{mg}$ of GRA/kg of body weight the first week of age, given a water intake of $32 \mathrm{~mL} /$ day and an initial body weight of $40 \mathrm{~g}$. During the last week of this trial, the dose was only $5 \mathrm{mg}$ of GRA $/ \mathrm{kg}$ of body weight, considering a water intake of $245 \mathrm{~mL} /$ day and a body weight of 3 $\mathrm{kg}$. Although these doses could be regarded as slightly high in terms of the referred values for humans, no side effects or any form of toxicity was observed in the tested broiler chickens. However, dose-response relationships with various chemical derivatives of glycyrrhizic acid, as well as detailed animal toxicological studies, are warranted before this active principle can be considered for use at a commercial scale.

The reasons for the better performance obtained with glycyrrhizic acid remain to be determined. However, it is tempting to speculate that the apparent activation of the immune system may be at least partially responsible for the growth-promoting effects observed. Cell-mediated immune modulation is here advanced, based on the well-defined increase in cortex thickness of the thymus. The thymus produces smaller lymphocytes and is responsible for cell mediated immunity, including immunosurveillance (Janeyway et al., 1988); hence, thymus cortex thickness test has been accepted as a reliable proof of cell-mediated immune response (Gholamiandehkordi et al., 2004). In addition, better humoral response to Newcastle virus vaccination in the glycyrrhizic acid-treated broilers was detected, as shown by the 1 log difference in hemagglutinating antibody titers against this virus, indicating an immunomodulating effect (Langman \& Cohn, 1993). A further indication of immune modulation is the observed increments in lymphocyte counts in GRA-treated chickens (Arstila, 1996) and perhaps in thrombocyte counts. Thrombocytes are the most abundant circulating cells next to red blood cells in the avian blood. Although avian thrombocytes are homologous in function to mammalian platelets and contribute to inflammatory responses upon stimulation with various microbial stimulants, some observed responses depart from the standardized model ascribed to innate cells. For example, chicken thrombocytes constitutively express transcripts for different toll-like receptors of the innate immune system that are crucial 
Ocampo CL, Gómez-Verduzco G, Tapia-Perez G, Gutierrez OL, Sumano LH

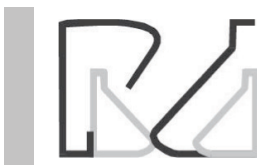

for a vigorous immune response. They express the major histocompatibility complex II and co-stimulatory molecules CD40, CD80, and CD86 (Ferdous et al., 2008). In addition of being unconventional, these expressions resemble innate effector cells in function and have a unique role in affecting adaptive immunity in chickens (Scott \& Owens, 2008). It has been shown that the in-vitro treatment of thrombocytes induces iNOS gene expression (Ferdous, 2014); yet, standard vaccination appears to be insufficient to stimulate chicken thrombocytes to increase its numbers or induce the expression of pro-inflammatory mediators (Ferdous, 2014). These aspects were not measured in this experiment; however, the observed increment in the number of thrombocytes after GRA administration may suggest a corresponding increment in these functions. However, such a proposal awaits further research before it can be accepted. Thus, if indeed there is an immunomodulatory effect induced by GRA, this could have had an important role in enhancing the flock's health, and consequently the weight gain, as performance parameters are directly linked to health.

There are no other studies in poultry production to compare the results here presented. However, in humans, positive effects on health derived from the antioxidant and immunomodulatory effects of the commercial glycyrrhizic acid preparation in patients with chronic hepatitis, have been observed (Vilar et al., 2009; Gomez, et al., 2010; García, et al., 2010; Kang \& Zohou, 2005). Liver-protective effects of GRA in broilers was not the primary goal of this trial, and the basic parameters obtained for liver integrity showed no clear information. Assessing a liver-protective effect of GRA is a particularly difficult task considering the short lifespan of broiler chickens and the aggressive nature of some etiologies e.g., aflatoxins.

Conflict of interest. The authors declare that they have no conflict of interest.

\section{REFERENCES}

Arbuckle JL. IBM SPSS $®$ AmosTM 19 user's guide. Crawfordville: Amos Development Corporation; 1995.

Arstila TP. T cell subset and the activation of $\gamma / \delta$ T cells In: Vainio O, Hof BA, editors. Immunology and developmental biology of the chicken. Berlin: Springer; 1996. p.71-77.

Badam L. In vitro studies of the effect of glycyrrhizin from the Indian Glycyrrhizaglabra Linn on some RNA and DNA virus. Indian Journal of Pharmacology 1994;26: 194-199.

Brugh M, Beard CW, Wilkins WS. The influence of test conditions of Newcastle disease hemagglutination-inhibition titers. Avian Diseases 1978;22:320-328.
Effects of Glycyrrhizic Acid on Productive and

Immune Parameters of Broilers

BuchnerA, Erdfelder E, Faul F. How to use G*Power [cited 2013 Jan] Available from: http://www.psycho.uni-duesseldorf.de/aap/projects/ gpower/how_to_use_gpower.html.

Castanon J. History of the use of Antibiotics as Growth Promoters in European Poultry Feeds. Journal Poultry Science 2007;86:2466-2471.

Chavali SR, Francis T, Campbell JB. An in vitro study of immunomodulatory effects of some saponins. International Journal of Immunopharmacology $1987 ; 9: 675-683$

Cox CM, Dalloul AR. Beta glucans as immunomodulators in poultry. Use and applications. Avian Biology Research 2010;3:171-178.

Dai JH. Glycyrrhizin enhances interleukin-12 production in peritoneal macrophages. Immunology 2010;103:235-243.

Dein FJ. Laboratory manual of avian hematology. East Northport: Association of Avian Veterinarians; 1984

Durrani FR, Sana U, Chand N, Durrani A, Akhtar S. Using aqueous extract of aloe gel as anticoccidial and immunostimulant agent in broiler production. Sarhad Journal of Agriculture 2008;24:665-669.

Edelman AS, Sánchez LP, Robinson EM, Hochwald G, Thorbecke JG. Primary and secondary wattle swelling response to phytohemagglutinin as a measure of immunocompetence in chickens. Avian Diseases. 1985;30:105-111

Ferdous $F$, Maurice $D$, Scott $T$. Broiler chick thrombocyte response to lipopolysaccharide. Poultry Science 2008;87:61-63.

Ferdous F. The avian thrombocyte is a specialized immune cell [paper 1289]. Clemson University; 2014. Available from: http://tigerprints.clemson. edu/all_dissertations/1289.

Gholamiandehkordi AR, Timbermont L, Lanckriet A, Van Den Broeck W, Pedersen K, Dewulf J, et al. Quantification of gut lesions in a subclinical necrotic enteritis model. Avian Pathology 2007;36:375-382.

Gomez EV, Perez YM, Sanchez HV, Forment GR, Soler EA, Bertot LC, et al. Antioxidant and immunomodulatory effects of Viusid $\circledast$ in patients with chronic hepatitis C. World Journal Gastroenterology 2010;16:26382647.

Gomis SL, Babiuk L, Godson DL, Allan B, Thrush T, Towsend H, et al. Protection of chickens against Escherichia coli infections by DNA Containing CpG Motifs. Infect and Immunolog 2003;71:857-863.

Hirabayashi K, Iwata S, Matsumoto H, Mori T, Shibata S, Baba M, et al. Antiviral activities of glycyrrhizin and its modified compounds against human immunodeficiency virus type 1 (HIV-1) and herpes simplex type 1 (HSV-1), in vitro. Chemical and Pharmaceuticall Bulletin 1991;39:112-115

Hoever G, Baltina L, Michaelis L, Antiviral activity of glycyrrhizic acid derivatives against SARS-coronavirus. Journal of Medicinal Chemistry 2005; $48: 1256-1259$.

Janeyway CA, Jones B, Hayday A. Specificity and function of T-cell bearing ãä receptors. Immunology Today 1988;9:73-76.

Kaiser P. Advances in avian immunology — prospects for disease control: a review. Avian Pathology 2010;39:309-324.

Kang YJ, Zhou Z. Zinc prevention and treatment of alcoholic liver disease. Molecular Aspects of Medicine 2005;26:391-404.

Krausse R, Bielenberg J, Blaschek W, Ullman U. In vitro anti-Helicobacter pylori activity of extractumliquiritiae, glycyrrhizin and its metabolites. Journal of Antimicrob. Chemother 2004;54:243-246 
Ocampo CL, Gómez-Verduzco G, Tapia-Perez G, Gutierrez OL, Sumano LH

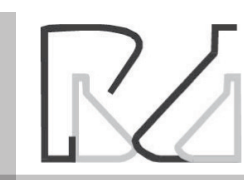

Effects of Glycyrrhizic Acid on Productive and

Immune Parameters of Broilers
Lanckriet W, Corrier DE, DeLoach JR. Evaluation of cell-mediated, cutaneous basophilic hypersensitivity in young chickens by an interdigital skin test. Poultry Science 1990;69:403-408.

Langman RE, Cohn MA. Theory of the ontogeny of the chicken humoral immune system: cosequences of diversification by gene hyperconversion and its extension to rabbit. Research Immunology 1993;144:422-446.

Lee $\mathrm{CH}$, Park SW, Kim YS, Kang SS, Kim JA, Lee JSH, et al. Protective mechanism of glycyrrhizin on acute liver injury induced by carbon tetrachloride in mice. Biology and Pharmaceutical Bulletin 2007;30:1898-1904

Lin JC. Mechanism of action of glycyrrizic acid in inhibition of Epstein-Barr virus replication in vitro. Antiviral Research 2003;59:41-47.

Lo $\mathrm{HH}$. Glycyrrhizinic acid inhibits arylamine N-acetyltransferase activity in Klebsiella pneumoniae in vitro. Journal of Applied Toxicology 1997; 17:385-390.

Ocampo CL, Chavez B, Tapia G, Ibarra C, Sumano H. Efficacy of a pharmaceutical preparation base on glycyrrizic acid in a challenge study of White spot síndrome in White shrimp. Aquaculture 2007;428429:280-283

Ohtsuki K, Ishida N. Inhibitory effect of glycyrrhizin on polypeptide phosphorylation by polypeptide dependent protein kinase (kinase P) in vitro. Biochemical and Biophysical Research Communication 1988:157:597-604
Ortiz M, Petrone VM, Tellez G, Fehéruári T. Histological evaluation of immune organs in chicken embryos inoculated with Marek's disease virus and lymphokines. Acta Veterinaria Hungarica 2001;49:163-174.

Pompei RO, Flore MA, Marcialis A, Pani A, Loddo B. Glycyrrhizic acid inhibits virus growth and inactivates virus particles. Nature 1979;281:689-690.

Scott TR, Owens MD. Thrombocytes respond to lipopolysaccharide through Toll-like receptor-4, and MAP kinase and NF- $\kappa B$ pathways leading to expression of interleukin- 6 and cyclooxygenase- 2 with production of prostaglandin E2. Molecular Immunology 2008;45:1001-1008.

Størmer FC, Reistad R, Alexander J. Glycyrrhizic acid in liquorice--evaluation of health hazard. Food Chemical Toxicology 1993;31:303-12.

Sugawara I. Human Interferon gamma (IFN-gamma) containing cells bear various surface phenotypic markers. Microbiology and Immunology 1986:30:1049-1059

Vilar GE, Rodriguez D, Miranda A, Gra-Oramas B, Arus SE, Llanio NR, et al. Clinical trial: a nutritional supplement Viusid, in combination with diet and exercise, in patients with nonalcoholic fatty liver disease Alimentary Pharmacology and Therapeutics 2009;15:999-1009.

Vilar GE, Oramas B, Soler E, Llanio NR, Ruenes DC. Viusid, a nutritional supplement, in combination with interferon alpha-2b and ribavirin in patients with chronic hepatitis C. Liver Internacional 2007;27:247-259. 